\title{
Wunderlich Syndrome, Tuberous Sclerosis-Related Giant Renal Angiomyolipoma Rupture: Case Report
}

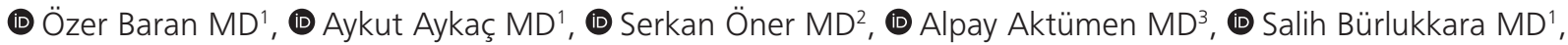 \\ (D) Mehmet Melih Sunay MD1, (D) Hakkı Uğur Özok MD \\ 'Karabük University Faculty of Medicine, Department of Urology, Karabük, Turkey \\ ${ }^{2}$ Karabük University Faculty of Medicine, Department of Radiology, Karabük, Turkey \\ ${ }^{3}$ Karabük University Faculty of Medicine, Department of Pathology, Karabük, Turkey
}

\begin{abstract}
Angiomyolipoma (AML) is a mesenchymal tumor of the kidney that is composed of morphologically abnormal smooth muscle cells, blood vessels, and adipose-like foci. Renal AML is usually clinically asymptomatic and detected incidentally during imaging. Rarely, renal AML can cause life-threatening spontaneous massive retroperitoneal hemorrhage, known as Wunderlich syndrome. A 39-year-old man with tuberous sclerosis was admitted to the emergency room with left flank pain, hematuria, and nausea. On physical examination, there was a hard sensitive mass extending from the upper left half of the abdomen to the midline. Left renal AML and extensive retroperitoneal hematoma measuring about 360×220x195 mm were detected on abdominal computed tomography. The patient exhibited signs of hypovolemic shock and emergency total nephrectomy was performed. He was discharged from the intensive care unit on postoperative day 1 and from the hospital on day 5 .
\end{abstract}

Keywords: Tuberous sclerosis, angiomyolipoma, Wunderlich syndrome

\section{Introduction}

Renal angiomyolipoma (AML) is a mesenchymal tumor of the kidney that is composed of morphologically abnormal blood vessels, smooth muscle cells, and adipose-like foci (1). Renal AML is usually clinically asymptomatic and may be detected incidentally during imaging. AMLs may become symptomatic as they increase in size. Rarely, renal AML can cause spontaneous massive hemorrhage in the renal subcapsular and/or perirenal area, which is a potentially life-threatening condition also known as Wunderlich syndrome (2).

Here we present a rare case of Tuberous sclerosis syndrome with hypovolemic shock (Wunderlich syndrome) after left renal AML rupture.

\section{Case Presentation}

A 39-year-old male patient was evaluated in the emergency department for left flank pain, hematuria, and nausea. From his medical history it was learned that he had tuberous sclerosis and was under regular follow-up due to bilateral renal AMLs. The patient also had mental retardation and was receiving antiepileptic therapy due to epilepsy. He had no history of anticoagulant use. On physical examination, a painful hard mass extending from the upper left region of the abdomen to the umbilical region was palpated. Numerous nodular skin lesions (adenoma sebaceum) were apparent between the nasal wings and the cheek. His arterial blood pressure was $70 / 40 \mathrm{mmHg}$, pulse was tachycardic (125 beats/min), and body temperature was $36.2{ }^{\circ} \mathrm{C}$. In complete blood count, hemoglobin level was 
6.1 g/dL and hematocrit was 17.7\%; serum biochemistry and coagulation tests were normal. Emergency full abdomen computed tomography (CT) with radiopaque contrast was performed. The CT scan revealed solid masses consistent with renal AML measuring $230 \times 164 \times 109 \mathrm{~mm}$ on the right and $360 \times 220 \times 195 \mathrm{~mm}$ on the left, and a large hematoma in the left retroperitoneal space (Figure 1). The patient underwent emergency laparotomy. An area of rupture extending to the collecting system of the anterior upper pole and extensive perirenal hematoma were detected. Left radical nephrectomy was performed. Two units of fresh frozen plasma and four units of erythrocyte suspension were transfused perioperatively. Postoperatively, the patient was intubated and admitted to the intensive care unit. He was extubated and transferred to an inpatient unit on postoperative day 1 and discharged on postoperative day 5 .

On macroscopic examination, the tumor appeared to be an encapsulated mass measuring $34 \times 21 \times 9 \mathrm{~cm}$ in size and weighing approximately $3100 \mathrm{~g}$ Cross-sectional appearance was solid and yellow-gray in color with hemorrhages in some areas (Figure 2). Pathological examination of sections stained with hematoxylin and eosin revealed tumor tissue separated from the normal renal parenchyma by a smooth border and composed of vascular structures, myoid spindle cells, and mature fat tissue with no cellular atypia or mitosis. Immunohistochemical staining was positive for smooth muscle actin, vimentin, and HMB-45, and negative for CD68 and CD117. CD31 staining was observed in the vascular endothelial cells. The Ki-67 index was $0-1 \%$ in tumor cells, and the findings were considered consistent with renal AML.

The data used in this report was obtained with the consent of the patient's relatives.

\section{Discussion}

Tuberous sclerosis was described in 1862 by Von Recklinghausen after detecting sclerotic foci and cardiac tumors in autopsies (3). The term tuberous sclerosis complex (TSC) is now preferred due to the widespread systemic involvement of the disease. TSC is a rare genetic disease that manifests with epilepsy, mental retardation, and facial angioma (Vogt's triad) (4).

TSC can involve the brain, kidneys, heart, skin, eyes, bones, and lungs. Neurologic involvement is the most common, followed by renal involvement, which is present in $60-75 \%$ of cases (5). AMLs occur in $70-80 \%$ of tuberous sclerosis patients with renal involvement, renal cysts in 20\%, and renal cancer is also seen in rare cases (6). There are two different types of renal AML: the first type occurs concomitantly with different diseases such as tuberous sclerosis, von Hippel Lindau, and von Recklinghausen neurofibromatosis, while the second type is isolated. The first type (20\%) of renal AML is generally bilateral, multiple, and symptomatic and affects both sexes equally. The second, isolated type (80\%) are single asymptomatic lesions with a female/male ratio of $4: 1$ and usually occur in women 50-60 years of age. Renal AMLs may be detected in $40-80 \%$ of patients with tuberous sclerosis (1).

AMLs are usually asymptomatic and often detected incidentally by radiological imaging (2). As the AML increases in size,

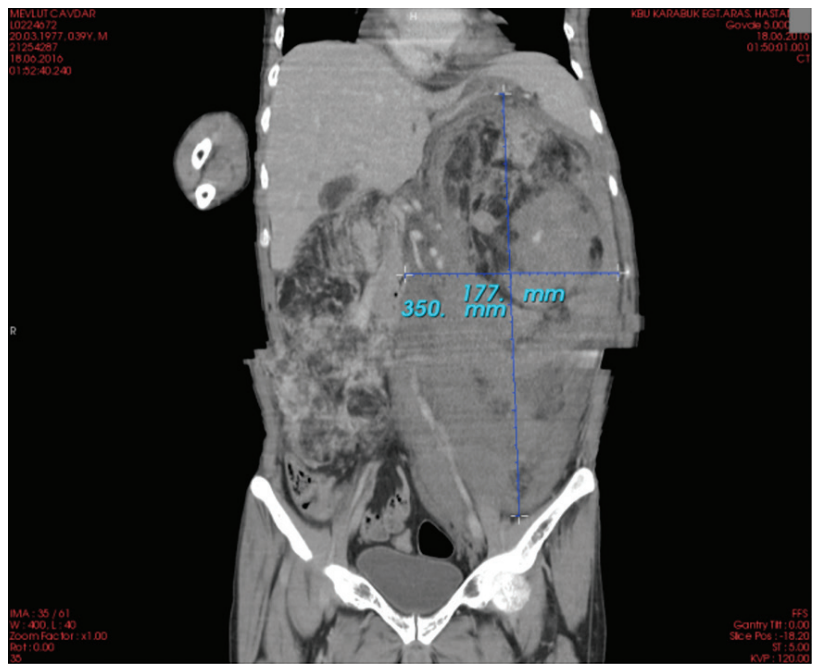

Figure 1. Computed tomography image of ruptured angiomyolipoma

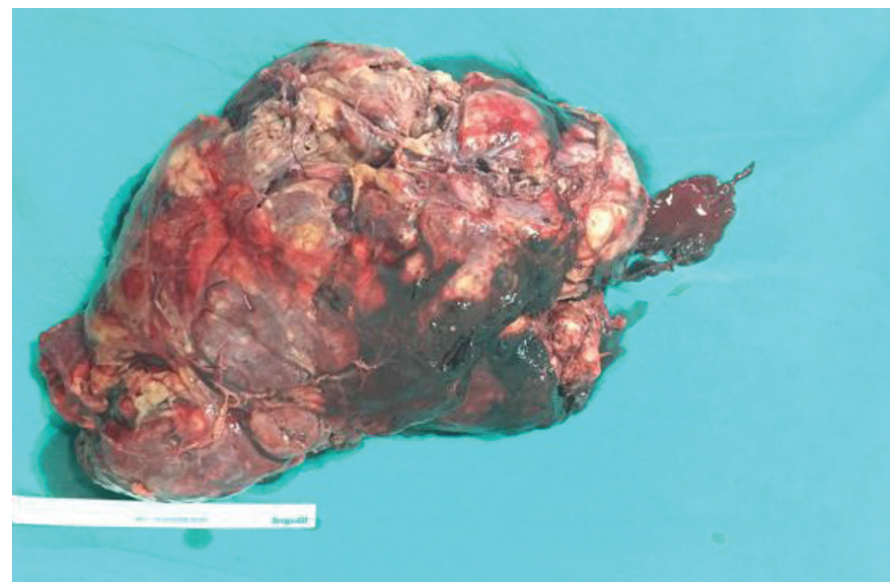

Figure 2. Macroscopic view of nephrectomy specimen

patients may present to the clinic with flank pain, palpable abdominal mass, or hematuria. One of the most dangerous clinical manifestations is spontaneous hemorrhage into the subcapsular and/or perirenal area, characterized by the classic triad of acute abdominal pain, palpable abdominal mass, and hypovolemic shock. This condition is called Wunderlich syndrome (2). A correlation has been observed between tumor size and hemorrhage risk. Oesterling et al. (7) reported that $82 \%$ of patients with AMLs over $4 \mathrm{~cm}$ in size were symptomatic, $9 \%$ of whom were in hemorrhagic shock at the time of diagnosis, whereas the symptomatic rate among patients with tumors smaller than $4 \mathrm{~cm}$ was $23 \%$. Çalışkan et al. (8) determined that the main factors affecting the growth and symptomatic development of AMLs were tumor size, the presence of multiple tumors, and having tuberous sclerosis. In another study, Steiner et al. (9) also determined that patients with tuberous sclerosis require surgical intervention more often because they often have bilateral masses, they are younger, and their tumors are larger. Therefore, they emphasized the high risk of requiring surgery or developing symptoms in the presence of AML larger than $4 \mathrm{~cm}$ or TSC (9). 
To the best of our knowledge, the largest unilateral AML to date, reported by Taneja and Singh (10) was $39 \times 29 \times 9 \mathrm{~cm}$ in size and weighed $7500 \mathrm{~g} \mathrm{Kalsi}$ et al. (11) reported a case of TSC-associated bilateral renal AML with $30 \times 21 \times 13 \mathrm{~cm}$ and $30 \times 18 \times 10 \mathrm{~cm}$ tumors and a total tumor burden of $7843 \mathrm{~g}$. Mistry et al. (12) reported a total tumor burden of $8305 \mathrm{cc}$ in a patient with bilateral AMLs $29 \times 27.5 \times 15.5 \mathrm{~cm}$ and $30 \times 19 \times 13 \mathrm{~cm}$ in size, the highest tumor burden reported in this literature. In our case, we detected as a mass weighing approximately 3100 $\mathrm{g}$ and measuring $34 \times 21 \times 9 \mathrm{~cm}$ in size.

Monitoring is the first choice for asymptomatic AMLs smaller than $4 \mathrm{~cm}$. Guidelines recommend imaging for renal morbidity every 1-3 years in patients with tuberous sclerosis (13). Treatment options should be evaluated based on tumor size, presence of TSC, and number of tumors. Selective arterial embolization, partial nephrectomy, and total nephrectomy are other treatment alternatives (14). Selective arterial embolization may be recommended for selected patients with solitary masses or hemorrhagic AML. In patients with tuberous sclerosis, pharmacologic approaches are currently recommended as firstline treatment options for AMLs larger than $3 \mathrm{~cm}$ and especially those exhibiting growth. There have been reports of significant response in tumor size with the mammalian target of rapamycin inhibitors (15).

A ruptured $\mathrm{AML}$ causing retroperitoneal hemorrhage can lead to life-threatening hypovolemic shock. Large renal AMLs should be monitored closely and treated electively. Partial or total nephrectomy may be life-saving in patients who develop Wunderlich syndrome.

\section{Ethics}

Informed Consent: It was taken.

Peer-review: Internally peer-reviewed.

\section{Authorship Contributions}

Surgical and Medical Practices: Ö.B., Concept: Ö.B., A.A., Design: Ö.B., A.A., Data Collection or Processing: S.B., Analysis or Interpretation: A.A., S.Ö., M.M.S., Literature Search: A.A., H.U.Ö., Writing: A.A.

Conflict of Interest: No conflict of interest was declared by the authors.
Financial Disclosure: The authors declared that this study received no financial support.

\section{References}

1. Ashebu SD, Dahniya MH, Elshebiny $\mathrm{YH}$, et al. Giant bleeding renal angiomyolipoma: Diagnosis and management. Australas Radiol 2002;46:115-118.

2. Mongha R, Bansal P, Dutta A, et al. Wunderlich's syndrome with hepatic angiomyolipoma in tuberous sclerosis. Indian J Cancer 2008;45:64-66.

3. Hanno R, Beck R. Tuberous Sclerosis. Neurol Clin 1987;5:351-359.

4. Hurst JS, Wilcoski S. Recognizing an index case of tuberous sclerosis. Am Fam Physician 2000;61:703-708.

5. O'Callaghan FJ, Noakes MJ, Martyn CN, Osborne JP. An epidemiological study of renal pathology in tuberous sclerosis complex. BJU Int 2004;94:853-857.

6. Stillwell TJ, Gomez MR, Kelalis PP. Renal lesions in tuberous sclerosis. J Urol 1987;138:477-481.

7. Oesterling JE, Fishman EK, Goldman SM, Marshall FF. The management of renal angiomyolipoma. J Urol 1986;135:1121-1124.

8. Çalışkan Z, Vuruşkan H, Kordan $Y$, ve ark. Kliniğimizdeki böbrek anjiomiyolipomlu olguların seyri. Türk Üroloji Dergisi 2006;32:43-47.

9. Steiner MS, Goldman SM, Fishman EK, Mashall FF. The natural history of renal angiomyolipoma. J Urol 1993;150:1782-1786.

10. Taneja R, Singh V. Giant renal angiomyolipoma: unusual cause of huge abdominal mass. J Clin Imaging Sci 2013;3:56.

11. Kalsi JS, Minhas S, Arya M, et al. Massive bilateral angiomyolipomas resulting in respiratory failure. BJU Int 2002;90:968-969.

12. Mistry KA, Sood D, Bhoil R, et al. A Classic Case of Tuberous Sclerosis with Multisystem Involvement Including Giant Bilateral Renal Angiomyolipomas Presenting as Massive Hematuria. Pol J Radiol 2015;80:435-441.

13. Krueger DA, Northrup H; International Tuberous Sclerosis Complex Consensus Group. Tuberous sclerosis complex surveillance and management: recommendations of the 2012 International Tuberous Sclerosis Complex Consensus Conference. Pediatr Neurol 2013;49:255-265.

14. Murray TE, Doyle F, Lee M. Transarterial Embolization of Angiomyolipoma: A Systematic Review. J Urol 2015;194:635-639.

15. Franz DN, Belousova E, Sparagana S, et al. Long-Term Use of Everolimus in Patients with Tuberous Sclerosis Complex: Final Results from the EXIST-1Study. PLoS One 2016;11:e0158476. 